\title{
Inhibitory effects of adrenocorticotrophin or corticosterone on progesterone secretion during mid-pregnancy in rats
}

\author{
H. Kato, K. Nanjo, F. Numa, Y. Nakamura, K. Ueda, H. Inoguchi \\ and T. Torigoe
}

Department of Obstetrics and Gynecology, Yamaguchi University School of Medicine, 1144 Kogushi, Ube, 755 Japan

\begin{abstract}
Summary. Conceptus number was reduced to one on Day 7 of pregnancy in rats by aspirating all but a single conceptus (Group E) or left at $\geq 8$ conceptuses (Group C). In Group $E$ rats, serum progesterone concentrations remained low from Day 12 until autopsy at Day 21. Hypophysectomy on Day 12 significantly increased serum progesterone values after Day 17 of pregnancy, and these increases were blocked by treatment with ACTH (10 U/day, i.p., Days 12-17). Adrenalectomy on Day 12 also induced slight, but statistically significant, increases in serum progesterone concentration after Day 17, and these were overcome by implantation of a $10 \mathrm{mg}$ capsule of corticosterone. In Group C rats, hypophysectomy or adrenalectomy on Day 12 did not change serum progesterone concentrations, but $40 \mathrm{U} \mathrm{ACTH/day} \mathrm{inhibited}$ progesterone secretion. We conclude from these results that the pituitary-adrenal system exerts inhibitory effects on progesterone secretion during mid-pregnancy in rats.
\end{abstract}

Keywords: ACTH; corticosterone; corpus luteum; rat; pregnancy

\section{Introduction}

Generally, luteal function of pregnant rats is regulated during the second half of pregnancy by placental hormones (Greenwald \& Rothchild, 1968). However, there are several reports that some other factors might be involved in the control of luteal function during mid-pregnancy (Pepe \& Rothchild, 1972; Gordon \& Sherwood, 1982; Kato et al., 1982; Rodway \& Garris, 1982; Ochiai et al., 1983). Of particular interest are the luteolytic effects of the pituitary, which are apparent after Day 12 of pregnancy in rats bearing a single conceptus (Ochiai et al., 1983). When the number of conceptuses was reduced to one by aspirating all but one conceptus on Day 7 of pregnancy, serum progesterone concentrations remained at or below the value of Day 12 to the end of the pregnancy (Kato et al., 1979). Hypophysectomy between Days 12 and 18 of pregnancy in rats bearing only one conceptus increased serum progesterone concentrations to values normally observed in rats bearing a full complement of conceptuses (Ochiai et al., 1983). The inhibitory effects of the pituitary on luteal function seem to be eliminated by conceptus-derived substances, e.g. the placental hormones, because hypophysectomy of rats with a full complement of conceptuses did not further increase the progesterone values, but just prolonged the decrease in serum progesterone concentrations (Pepe \& Rothchild, 1972). However, the detailed mechanism through which the pituitary can inhibit luteal function has not been clearly demonstrated. ACTH has been reported to interrupt pregnancy in rats (Yang et al., 1969) and Hellar \& de Nicola (1983) also demonstrated that corticoids inhibited the progesterone synthesis in rat placentas. The present study was undertaken to 
investigate the possible role of the pituitary-adrenal axis in the regulation of luteal function in pregnant rats.

\section{Materials and Methods}

Sprague-Dawley rats, weighing $220-270 \mathrm{~g}$, were housed under controlled conditions (lights on 05:00-19:00 h) with free access to standard rat chow and water. Day 1 of pregnancy was the day that spermatozoa were found in the vaginal smear. All operations, blood sampling, and autopsies were done under light ether anaesthesia between 10:00 and $14: 00 \mathrm{~h}$. On Day.7, each rat was laparotomized and rats with 8 or more conceptuses were included in these experiments. In Group E, conceptus number was adjusted to one on Day 7 of pregnancy by aspirating all conceptuses except the one nearest the ovary as described previously (Kato et al., 1979). Rats in Group C received only laparotomy on Day 7 to confirm the number of conceptuses.

Each group of rats was further divided into 6 subgroups (at least 5 animals each), and received one of the following treatments: (1) hypophysectomy on Day 12 plus daily injection of ACTH (Cortrosyn z, Daiichi Pharm. Co., Ltd, Tokyo, Japan; 10 or $40 \mathrm{U} /$ day, i.p.) from Day 12 to 17 ; (2) hypophysectomy on Day 12 plus daily injection of $0.3 \mathrm{ml}$ saline $(0 \cdot 15 \mathrm{M})$ from Day 12 to 17; (3) sham hypophysectomy on Day 12; (4) bilateral adrenalectomy on Day 12 plus implantation of corticosterone Silastic capsule beneath the dorsal skin $(10 \mathrm{mg} / \mathrm{rat})$ between Day 12 and 17 . (Pilot studies indicated that the implantation of a $10-\mathrm{mg}$ corticosterone capsule in adrenalectomized male rats resulted in plasma corticosterone concentrations of $150 \mathrm{ng} / \mathrm{ml}$, which are approximately equai to values in intact pregnant rats) (Dupouy et al., 1975; Chatelain et al., 1980.); (5) bilateral adrenalectomy on Day 12 plus implantation of a blank Silastic capsule; and (6) sham adrenalectomy on Day 12. Since there were no significant differences in serum progesterone concentrations or organ weights between the sham-hypophysectomy (Subgroup 3) and sham-adrenalectomy (Subgroup 6) groups, they were regarded as one group (sham-operation rats).

Hypophysectomy was performed by the parapharyngeal approach. For sham hypophysectomy, the hole was made at the base of the skull, without aspirating the pituitary. Sham-adrenalectomized rats received laparotomy. Completeness of the operations was assessed at autopsy by the absence of pituitary remnants in the fossa, or by the absence of adrenal glands at the operation sites.

Blood samples (approximately $0.6 \mathrm{ml}$ ) were obtained by jugular venepuncture under light ether anaesthesia, and serum samples were stored until assay at $-70^{\circ} \mathrm{C}$. Serum progesterone concentrations were determined in duplicate by a radioimmunoassay as described previously (Kato et al., 1982). The progesterone antiserum was raised against I l $\alpha$-hydroxyprogesterone conjugated to BSA, and cross-reacted $58 \%$ with $11 \alpha$-hydroxyprogesterone, $12 \%$ with 11 $\beta$-hydroxyprogesterone, $11 \%$ with $5 \alpha-3,20$-pregnanedione, $3 \%$ with deoxycorticosterone, $2 \cdot 5 \%$ with $20 \alpha-$ dihydroprogesterone, $1.7 \%$ with $17 \alpha$-hydroxyprogesterone, and $<1 \%$ with other progestagens, oestrogens, androgens and corticoids. The minimum sensitivity of the assay was $1 \mathrm{ng} / \mathrm{ml}$, and the intra- and inter-assay coefficients of variations were $7 \cdot 0 \%$ and $14.4 \%$ respectively. The additions of 50,100 and $200 \mathrm{ng}$ progesterone to pooled female rat serum yielded recoveries of $103 \cdot 3 \pm 1 \cdot 0 \%, 88 \cdot 4 \pm 2 \cdot 1 \%$ and $89 \cdot 2 \pm 2 \cdot 1 \%$, respectively.

All rats were autopsied on Day 21, and the weights of the corpora lutea (CL), ovaries, adrenal glands, fetuses, and placentas were recorded.

All data were analysed by analysis of variance and new Duncan's multiple range test, and when appropriate, Student's $t$ test was used. A $P$ value of $<0.05$ was considered to be statistically significant.

\section{Results}

Serum progesterone concentrations in Group $\mathrm{E}$ rats remained at or below the values for rats on Day 12 until the end of pregnancy (Kato et al., 1979), and hypophysectomy on Day 12 significantly $(P<0.05)$ increased serum progesterone values on Days 17, 19 and 21, which confirmed the previous findings of Ochiai et al. (1983). Daily injections of $10 \mathrm{U}$ ACTH inhibited the rises in progesterone values induced by hypophysectomy (Fig. 1a). When Group E rats were adrenalectomized on Day 12, the progesterone concentrations also increased significantly $(P<0.05)$ after Day 17 , and this increase was suppressed, except on Day 21, by the corticosterone treatments (Fig. 2a).

Serum progesterone concentrations in Group $\mathrm{C}$ rats rose after Day 12, reaching peak values around Day 15, and fell on Day 21. Hypophysectomy on Day 12 did not cause any significant changes, except on Day 19 when the progesterone value was significantly $(P<0.05)$ lower than that in the sham-operation rats (Fig. 1b). Injection of $40 \mathrm{U}$ ACTH significantly $(P<0.01)$ decreased serum progesterone concentrations after Day 15 in the hypophysectomized Group $C$ rats. Adrenalectomy on Day 12 decreased serum progesterone on Days 19 and 21, but corticosterone treatments showed no effects (Fig. 2b). 


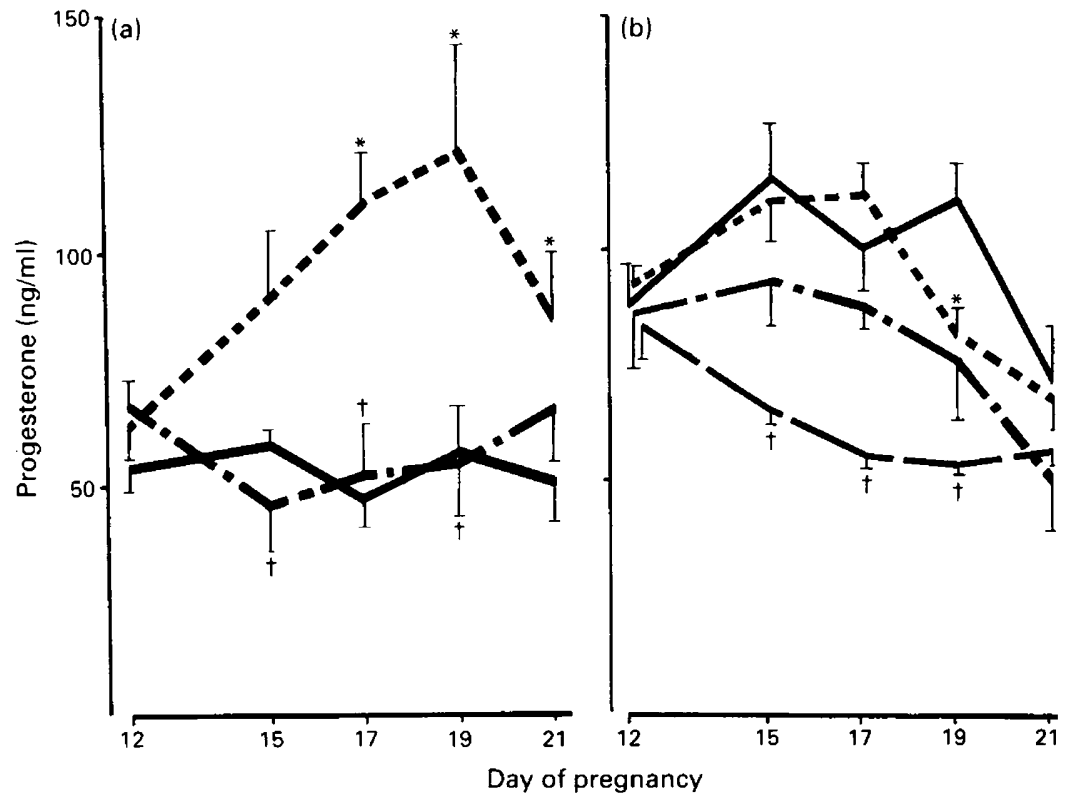

Fig. 1. Effects of hypophysectomy or ACTH treatment on serum progesterone concentrations in rats in (a) Group E and (b) Group $\mathrm{C}$ with sham-operation ( - ), hypophysectomy (-- ), or hypophysectomy plus ACTH $(10 \mathrm{U} \ldots-\ldots$; or $40 \mathrm{U}-\ldots)$. ${ }^{*} P<0.05$ compared with sham-operation group; $+P<0.05$ compared with hypophysectomy group.

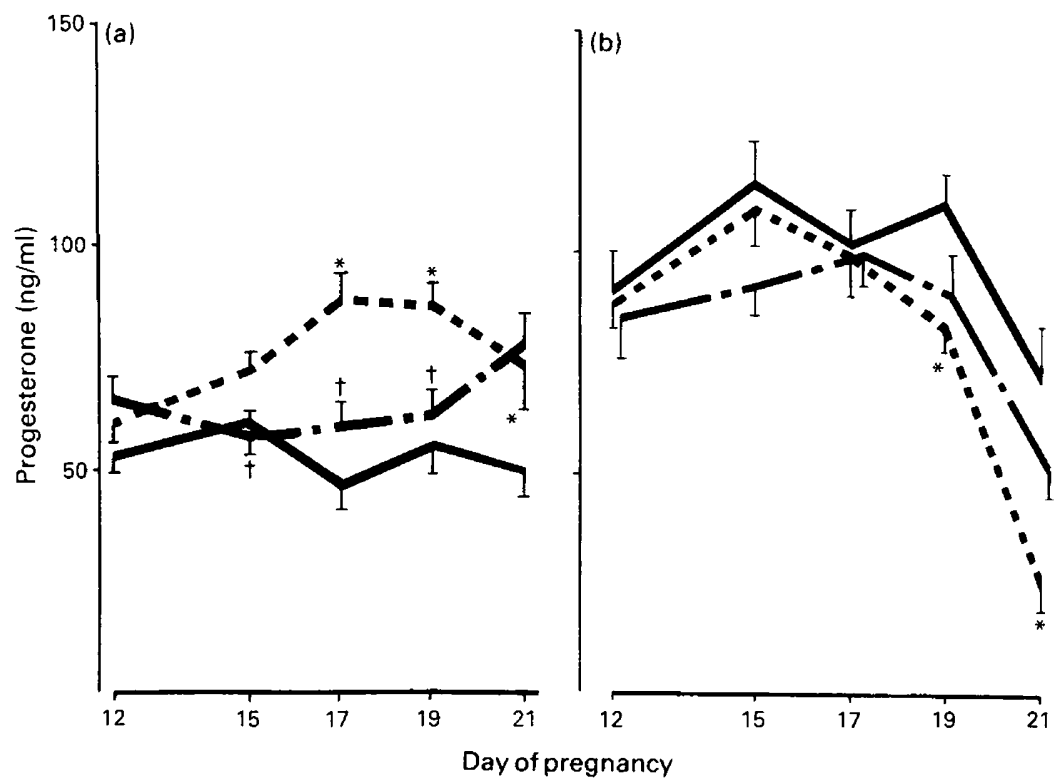

Fig. 2. Effects of adrenalectomy or corticosterone implantation on serum progesterone concentrations in rats in (a) Group $\mathrm{E}$ and (b) Group $\mathrm{C}$ with sham-operation ( - ), adrenalectomy $(---)$, or adrenalectomy plus corticosterone treatment $(---){ }^{*} P<0.05$ compared with sham-operation group; $\uparrow P<0.05$ compared with adrenalectomy group. 
Hypophysectomy or adrenalectomy significantly $(P<0.05)$ increased the weights of the CL in Group E rats, but not in Group C rats. Treatments with ACTH or corticosterone did not decrease the CL weights. However, ACTH treatments significantly $(P<0.05)$ decreased the weights of the fetuses and placentas in both groups of rats.

Table 1. Effects of the experimental treatments on the weights of corpora lutea, fetuses and placentas of rats in Groups $\mathrm{E}$ and $\mathrm{C}$

\begin{tabular}{|c|c|c|c|c|c|c|c|c|}
\hline \multirow[b]{2}{*}{ Treatment } & \multicolumn{4}{|c|}{ Group E ( 1 conceptus) } & \multicolumn{4}{|c|}{ Group $\mathrm{C}$ ( $\geq 8$ conceptuses) } \\
\hline & $\begin{array}{l}\text { No. of } \\
\text { rats }\end{array}$ & $\begin{array}{l}\mathrm{CL} \\
(\mathrm{mg})\end{array}$ & $\begin{array}{l}\text { Fetus } \\
(\mathrm{g})\end{array}$ & $\begin{array}{l}\text { Placenta } \\
\text { (mg) }\end{array}$ & $\begin{array}{l}\text { No. of } \\
\text { rats }\end{array}$ & $\begin{array}{c}\mathrm{CL} \\
(\mathrm{mg})\end{array}$ & $\begin{array}{l}\text { Fetus } \\
\text { (g) }\end{array}$ & $\begin{array}{l}\text { Placenta } \\
\text { (mg) }\end{array}$ \\
\hline Sham operation & 9 & $3 \cdot 1 \pm 0 \cdot 1$ & $4 \cdot 0 \pm 0 \cdot 1$ & $829 \pm 56$ & 5 & $4.5 \pm 0.2$ & $3 \cdot 5 \pm 0 \cdot 1$ & $443 \pm 27$ \\
\hline Hypophysectomy & 6 & $3 \cdot 4 \pm 0 \cdot 1^{\mathrm{a}}$ & $3 \cdot 6 \pm 0 \cdot 1$ & $727 \pm 68$ & 7 & $4 \cdot 0 \pm 0.2$ & $3 \cdot 2 \pm 0 \cdot 1^{\mathrm{a}}$ & $454 \pm 18$ \\
\hline $\begin{array}{c}\text { ACTH (10 U) } \\
\text { Hypophysectomy }+\end{array}$ & 9 & $3 \cdot 2 \pm 0 \cdot 1$ & $3 \cdot 1 \pm 0 \cdot 2^{b}$ & $498 \pm 52^{b}$ & 6 & $3.9 \pm 0.3$ & $2 \cdot 7 \pm 0 \cdot 1^{b}$ & $358 \pm 22^{\mathrm{b}}$ \\
\hline ACTH $(40 \mathrm{U})$ & & & & & 5 & $3 \cdot 6 \pm 0.2$ & $3 \cdot 0 \pm 0 \cdot 3$ & $323 \pm 54^{b}$ \\
\hline Adrenalectomy & 5 & $4 \cdot 0 \pm 0 \cdot 2^{a}$ & $3 \cdot 1 \pm 0 \cdot 1^{\mathrm{a}}$ & $676 \pm 53$ & 7 & $4.4 \pm 0.2$ & $2 \cdot 7 \pm 0 \cdot 2^{\mathrm{a}}$ & $409 \pm 18$ \\
\hline $\begin{array}{l}\text { Adrenalectomy }+ \\
\text { corticosterone }\end{array}$ & 6 & $4 \cdot 0 \pm 0 \cdot 3$ & $4 \cdot 0 \pm 0 \cdot 1^{c}$ & $743 \pm 92$ & 6 & $4 \cdot 5 \pm 0 \cdot 1$ & $2 \cdot 5 \pm 0 \cdot 1$ & $435 \pm 15$ \\
\hline
\end{tabular}

Values are mean \pm s.e.m. at autopsy on Day 21 .

${ }^{\mathrm{a}} P<0.05$ compared with sham-operation group; ${ }^{\mathrm{b}} P<0.05$ compared with hypophysectomy group; ${ }^{\mathrm{c}} P<0.05$ compared with adrenalectomy group.

\section{Discussion}

The present study clearly demonstrated that ACTH or corticosterone decreased circulating progesterone concentrations in rats with only 1 conceptus. Changes in the circulating progesterone levels generally reflect a change in the progesterone secretion rate (Pepe \& Rothchild, 1973; Rothchild et al., 1973). Although the luteolytic effect of ACTH and corticosterone was restricted in rats bearing a single conceptus, the present findings strongly suggest the involvement of the pituitary-adrenal system in the regulation of progesterone secretion by the $C L$ in pregnant rats.

It is not clear at present how ACTH or corticosterone influence luteal function. A direct action of $\mathrm{ACTH}$ on the $\mathrm{CL}$ is unlikely, because, in our preliminary studies using in-vitro incubation of luteal cells, ACTH by itself did not show any direct inhibitory effects on progesterone production. Furthermore, although adrenalectomy increased serum ACTH values (Chatelain et al., 1980), progesterone secretion was increased after adrenalectomy. Since ACTH stimulates the production of adrenocorticosteroids, and since corticosteroids inhibit progesterone production in the rat placenta (Hellar \& de Nicola, 1983), it is likely that ACTH exerts its inhibitory effects through the production of corticosteroids. This concept would fit with the present results that corticosterone treatments inhibited the adrenalectomy-induced rises in progesterone secretion in rats with 1 conceptus (Fig. 2a). LH has been demonstrated to have luteolytic effects in rats (Rothchild, 1965). However, if LH is also luteolytic in the rats with 1 conceptus, adrenalectomy might decrease progesterone secretion, because corticoids suppress LH secretion (Chatelain et al., 1980; Ribingston \& Schwartz, 1985).

Several reports have demonstrated that hypophysectomy in intact pregnant rats raised concentrations of serum placental lactogen (Daughaday et al., 1979; Ochiai et al., 1983; Blank \& Dufau, 1983 ) or chorionic gonadotrophin (Blank \& Dufau, 1983), and it is well documented that luteal 
function is mainly regulated by the placental luteotrophins during the second half of pregnancy in rats (Greenwald \& Rothchild, 1968). However, hypophysectomy does not increase serum progesterone concentrations in rats with a full complement of conceptuses (Fig. 1b; Pepe \& Rothchild, 1973; Ochiai et al., 1983). Furthermore, serum chorionic gonadotrophin values declined transiently around Day 16 (Blank \& Dufau, 1983) when serum progesterone concentrations remained high. These results suggest that progesterone secretion is not directly controlled by the placental hormone in pregnant rats. Ochiai et al. (1983) demonstrated that hypophysectomy in rats with 1 conceptus increased progesterone secretion without affecting placental lactogen levels. Also, the secretion of testosterone, another placental product to stimulate the luteal function, was not affected by hypophysectomy in rats with 1 or more conceptuses (Golos \& Sherwood, 1984). Although further extensive studies are needed to assess the influence of the pituitary-adrenal system on the production of the placental hormones in rats with 1 conceptus, the increases in progesterone secretion after hypophysectomy or adrenalectomy may not be due to the increase in the placental hormone.

Generally, plasma concentrations of corticosterone in pregnant rats declined from Day 12 to 15, and remained low until Day 17, followed by a rapid increase to term (Petropoulos \& Lau, 1973; Dupouy et al., 1975). Adrenalectomy on Day 14 resulted in significant decreases in plasma corticosterone levels on Days 16 and 17 (Dupouy et al., 1975; MacDonald \& Matt, 1984). After Day 18, however, corticosterone concentrations in the maternal circulation were directly related to the conceptus number (Dupouy et al., 1975), and were not influenced by adrenalectomy. In spite of these facts, serum progesterone concentrations remained higher after Day 19 of pregnancy in the adrenalectomized or hypophysectomized rats with 1 conceptus. It may be that the ability of the CL to produce progesterone has already been increased in adrenalectomized rats by Day 19 of pregnancy, or that there are some adrenal factors, other than corticosterone, that inhibit progesterone secretion after Day 19 of pregnancy.

It has been reported that the fetus participates in the regulation of luteal function (Kittinger et al., 1980). In the present study, ACTH treatment reduced the weights of the fetus and placenta (Table 1), which confirmed the previous report for mice (Paul \& D'Angelo, 1972). There are several reports that adrenalectomy or corticoid treatment of the mother affect fetal adrenal function (Knobil \& Briggs, 1954; Baldwin, 1979). Although Ochiai et al. (1983) showed no differences in progesterone secretion between rats with 1 placenta and those with 1 conceptus (i.e. 1 fetus plus 1 placenta), we cannot exclude the possibility that the maternal pituitary and/or adrenal factors may influence the fetus, which in turn exerts some effects on the luteal function.

Hypophysectomy or adrenalectomy did not increase serum progesterone concentrations in the rats with a full complement of conceptuses (Figs $1 \mathrm{~b}$ and $2 \mathrm{~b}$ ), but adrenalectomy did decrease progesterone values (Fig. 2b). Butterstein \& Hirst (1977) reported that adrenalectomy plus ovariectomy decreased serum progesterone concentrations much more than did ovariectomy alone. Adrenalectomy may simply eliminate the source of progesterone (MacDonald \& Matt, 1984), resulting in a decrease of circulating progesterone concentrations. In other words, the pituitaryadrenal system does not exert inhibitory effects on luteal function when more than one conceptus is present. In the present study, a higher dose of ACTH ( $40 \mathrm{U} /$ day) was required to suppress serum progesterone concentrations in rats with a full complement of conceptuses (Fig. 2b). Ochiai et al. (1983) have noted that the inhibitory effect of the pituitary would be eliminated by the placental hormones. The placental hormone may change the nature of the CL, or block the inhibitory effects of the pituitary-adrenal system either at the CL or some other sites (e.g. the uterus). In fact, the pituitary does not exert its inhibitory effects even in rats with 1 conceptus when the non-gravid part of the uterus is absent (Kato et al., 1982). Further studies are needed to assess the role of the pituitary-adrenal system, placental hormones and the uterus in the regulation of luteal function.

This work was supported in part by Grant-in-Aid (60771278) from the Ministry of Education, Japan. 


\section{References}

Baldwin, D.M. (1979) The effect of glucocorticoids on estrogen-dependent luteinizing hormone release in the ovariectomized rat and on gonadotropin secretion in the intact female rat. Endocrinology 105, 120-128.

Blank, M.S. \& Dufau, M.L. (1983) Rat chorionic gonadotropin: Augmentation of bioactivity in the absence of the pituitary. Endocrinology 112, 2200-2202.

Butterstein, G.M. \& Hirst, J.A. (1977) Serum progesterone and fetal morphology following ovariectomy and adrenalectomy in the pregnant rat. Biol. Reprod. 16, 654-660.

Chatelain, A., Dupouy, J-P. \& Allaume, P. (1980) Fetalmaternal adrenocorticotropin and corticosterone relationship in the rat: effects of maternal adrenalectomy. Endocrinology 106, 1297-1303.

Daughaday, W.H., Trivedi, B. \& Kapadia, M. (1979) The effect of hypophysectomy on rat chorionic somatomammotropin as measured by prolactin and growth hormone radioreceptor assays: possible significance in maintenance of somatomedin generation. Endocrinology 105, 210-214.

Dupouy, J.P., Coffigny, H. \& Magre, S. (1975) Maternal and foetal corticosterone levels during late pregnancy in rats. J. Endocr. 65, 347-352.

Golos, T.G. \& Sherwood, O.D. (1984) Evidence that the maternal pituitary suppresses the secretion of relaxin in the pregnant rat. Endocrinology 115, 1004-1010.

Gordon, W.L. \& Sherwood, O.D. (1982) Evidence that luteinizing hormone from the maternal pituitary gland may promote antepartum release of relaxin, luteolysis and birth in rats. Endocrinology 111, $1299-1310$.

Greenwald, G.S. \& Rothchild, I. (1968) Formation and maintenance of corpus lutea in laboratory animals. $J$. Anim. Sci. 27 (Suppl. 1), 139-161.

Hellar, C. \& de Nicola, A.F. (1983) Inhibition of progesterone synthesis in placenta by administration of dexamethasone to pregnant rats. J. Steroid Biochem. 19, 1339-1343.

Kato, H., Morishige, W.K. \& Rothchild, I. (1979) Quantitative relationship between the experimentally determined number of conceptuses and corpus luteum activity in the pregnant rat. Endocrinology 105, $846-850$.

Kato, H., Ueda, K., Tsutsui, H., Miyauchi, F. \& Torigoe, T. (1982) Role of the nongravid part of the uterus in the regulation of corpus luteum function in pregnant rats. Endocrinology 111, 2020-2024.

Kittinger, J.W., Gutierrez-Cernosek, R.M., Cernosek, S.F., Jr. \& Pasley, J.N. (1980) Effects of adreno- corticotropin on pregnancy and prolactin in mice. Endocrinology 107, 616-621.

Knobil, E. \& Briggs, F.N. (1954) Mechanism of fetal adrenal hypertrophy in the adrenalectomized pregnant rat. Fedn Proc. Fedn Am. Socs exp. Biol. 13, 80, Abstr.

MacDonald, G.J. \& Matt, D.W. (1984) Adrenal and placental steroid secretion during pregnancy in the rat. Endocrinology 114, 2068-2073.

Ochiai, K., Kato, H., Kelly, P.A. \& Rothchild, I. (1983) The importance of a luteolytic effect of the pituitary in understanding the placental control of the rat corpus luteum. Endocrinology 112, 1687-1695.

Paul, D.H. \& D'Angelo, S.A. (1972) Dexamethasone and corticosterone administration to pregnant rats: effects on pituitary-adrenocortical function in the newborn. Proc. Soc. exp. Biol. Med. 140, 1360-1364.

Pepe, G.J. \& Rothchild, I. (1972) The effect of hypophysectomy on day 12 of pregnancy on the serum progesterone level and time of parturition in the rat. Endocrinology 91, 1380-1385.

Pepe, G.J. \& Rothchild, I. (1973) Metabolic clearance rate of progesterone: comparison between ovariectomized, pregnant, pseudopregnant and deciduomabearing pseudopregnant rats. Endocrinology 93, $1200-1205$.

Petropoulos, E.A. \& Lau, C. (1973) Fetoplacental contribution to the maternal corticosteroid pool in LongEvans rats. J. Endocr. 59, 183-184.

Ribingston, S.J. \& Schwartz, N.B. (1985) Cortisol suppresses the $\mathrm{LH}$, but not the $\mathrm{FSH}$, response to gonadotropin-releasing hormone after orchidectomy. Endocrinology 116, 472-474.

Rodway, R.C. \& Garris, D.R. (1982) Potentiation by prolactin of the luteotrophic effect of oestradiol in the pregnant rat. Acta endocr., Copenh. 101, 287-292.

Rothchild, I. (1965) The corpus luteum-hypophysis relationship. The luteolytic effect of luteinizing hormone (LH) in the rat. Acta endocr., Copenh. 49, $107-119$.

Rothchild, I., Billiar, R.B., Kline, I.T. \& Pepe, G.J. (1973) The persistence of progesterone secretion in pregnant rats after hypophysectomy and hysterectomy: a comparison with pseudopregnant, deciduomata-bearing pseudopregnant, and lactating rats. J. Endocr. 57, 63-74.

Yang, W.H., Yang, W.P. \& Lin, L.L. (1969) Interruption of pregnancy in the rat by administration of ACTH. Endocrinology 84, 1282-1285.

Received 15 December 1987 